\title{
Elevated levels of plasma D-dimer predict a worse outcome in patients with nasopharyngeal carcinoma
}

\author{
Wen-Hui Chen ${ }^{1 \dagger}$, Lin-Quan Tang ${ }^{1,2+}$, Feng-Wei Wang ${ }^{1}$, Chang-Peng Li ${ }^{1}$, Xiao-Peng Tian ${ }^{1}$, Xiao-Xia Huang ${ }^{1}$, \\ Shi-Juan Mai ${ }^{1}$, Yi-Ji Liao', Hai-Xia Deng ${ }^{1}$, Qiu-Yan Chen ${ }^{1,2}$, Huai Liu ${ }^{1,2}$, Lu Zhang ${ }^{1,2}$, Shan-Shan Guo ${ }^{1,2}$, Li-Ting Liu ${ }^{1,2}$, \\ Shu-Mei Yan ${ }^{1,3}$, Chao-Feng Li ${ }^{1,4}$, Jing-Ping Zhang ${ }^{1,5}$, Qing Liu ${ }^{1,6}$, Xue-Wen Liu ${ }^{1,7}$, Li-Zhi Liu ${ }^{1,7}$, Hai-Qiang Mai ${ }^{1,2^{*}}$, \\ Mu-Sheng Zeng ${ }^{1 *}$ and Dan Xie
}

\begin{abstract}
Background: Hemostatic alterations occur during the development of cancer. Plasma D-dimer is a hypercoagulability and fibrinolytic system marker that is increased in patients with various solid tumours. The aim of this study was to evaluate the hemostatic status of nasopharyngeal carcinoma (NPC) patients by assessing plasma D-dimer levels to investigate its value as a prognostic marker.
\end{abstract}

Methods: We retrospectively analysed 717 patients with nasopharyngeal carcinoma, and we applied Cox regression and log-rank tests to assess the association of D-dimer levels with disease-free survival (DFS), distant metastasis-free survival (DMFS), and overall survival (OS). D-dimer levels were measured using a quantitative D-dimer latex agglutination assay.

Results: Using the 3rd quartile values $(0.8 \mu \mathrm{g} / \mathrm{L})$ as the optimal cut-offs, we found that patients with high D-dimer levels have a shorter 3-year DFS, $(79 \%, 95 \% \mathrm{Cl}(73.1-84.9))$ vs. $(69 \%, 95 \% \mathrm{Cl}(59.2-78.8))$, DMFS $(87 \%, 95 \% \mathrm{Cl}(83.1-90.9))$ vs. (77\%, 95\%Cl (69.2-84.8)), and overall survival (82\%, 95\%Cl (76.1-87.9)) vs. (76\%, 95\%Cl (66.2-85.8)). Multivariate analysis revealed that pre-treatment D-dimer levels and EBV DNA were significant independent factors for DFS, DMFS, and OS in NPC patients. Subgroup analyses indicated that the plasma D-dimer levels could effectively stratify patient prognosis for early cancer, advanced stage cancer, and patients with EBV DNA $\geq 4000$ copies $/ \mathrm{ml}$.

Conclusions: High D-dimer levels were associated with poor disease-free survival, distant metastasis-free survival, overall survival, and increased risk of mortality in NPC patients. Prospective trials are required to assess the prognostic value of D-dimer levels.

Keywords: Nasopharyngeal carcinoma, D-dimer, Survival

\section{Background}

Nasopharyngeal carcinoma (NPC) is one of the most common malignancies in southern China, southeastern Asia, and northern Africa. The lowest prevalence of NPC is found in white populations from Europe and the

\footnotetext{
* Correspondence: maihq@sysucc.org.cn; zengmsh@sysucc.org.cn; xied@mail.sysu.edu.cn

${ }^{\dagger}$ Equal contributors

'Sun Yat-sen University Cancer Center, State Key Laboratory of Oncology in South China; Collaborative Innovation Centre for Cancer Medicine,

Guangzhou 510060, P. R. China

${ }^{2}$ Department of Nasopharyngeal Carcinoma, Sun Yat-sen University Cancer Center, Guangzhou 510060, P. R. China

Full list of author information is available at the end of the article
}

United States [1-3]. Radiotherapy regimens are currently the primary treatment strategy for NPC patients. Although the TNM staging system [4] is currently the most powerful prognostic factor for NPC, patients with the same stage and similar treatment regimens have variable clinical outcomes. The expression of several specific biological markers have been used to provide additional prognostic information for NPC patients, including epidermal growth factor receptor [5], serum lactate dehydrogenase (LDH) [6], C-reactive protein (CRP) [7], and plasma Epstein-Barr virus DNA (EBV DNA) [8]. Several studies have investigated pre-treatment EBV DNA, 
which is used for disease monitoring and prognosis prediction in the clinic [8-10].

Several studies have suggested an association between a more aggressive cancer phenotype and hypercoagulability $[11,12]$. Interestingly, in the absence of venous thromboembolism (VTE), the systemic activation of blood coagulation and procoagulant changes in the hemostatic system are frequently been observed in cancer patients $[13,14]$. Patients with cancer and hypercoagulation have a higher risk of venous thrombosis and a poor prognosis [15]. It has been reported that many increased or decreased coagulation factors contribute to cancer growth, progression and metastasis [16]. The plasma D-dimer is a stable end product of fibrin degradation, and it is a useful biomarker for predicting venous thromboembolism (VTE) in cancer patients [17]. Increased D-dimer levels are related to tumour stage, tumour prognosis and lymph node involvement. Additionally, D-dimer levels are a negative prognostic indicator for several malignancies, including breast [18], colorectal [19], lung [20], and prostate cancer [21]. Elevated $\mathrm{D}$-dimer levels may reflect multifactorial interactions between carcinoma growth and the hemostatic-fibrinolytic system in malignancy. However, the clinical significance of D-dimer in nasopharyngeal carcinoma has not been established.

The purpose of this study was to analyse the prognostic value of plasma D-dimer levels in patients with NPC and evaluate the correlation between pre-treatment plasma D-dimer levels and clinical-pathological parameters. The results of our study will help predict NPC progression in patients and provide information for further treatment.

\section{Methods}

\section{Patient selection}

The principal inclusion criteria were as follows: (1) biopsyproven primary NPC, no radiotherapy, chemotherapy, or oncologic surgery history, and an ECOG of 0 to 2; (2) patient age $\geq 18$ years; (3) adequate hematologic, renal, and hepatic function (white blood cell count of $\geq 4000 / \mu \mathrm{L}$, platelet count of $\geq 100000 / \mathrm{UL}$, serum creatinine clearance $\geq 50 \mathrm{~mL} / \mathrm{min}$, total serum bilirubin concentration $<1.5 \mathrm{mg} / \mathrm{dL}$ ); and (4) available follow-up data. The following exclusion criteria were used for our study: (1) patients who had a history of venous thrombosis or anticoagulation therapy within 3 months before treatment; (2) patients with previous or coexisting cancer other than NPC; (3) pregnancy and lactation; or (4) stroke or neurosurgery within 6 months.

Between January 2008 and December 2011, a total of 717 consecutive non-distant-metastatic NPC patients (average age of 47, ranging from 29 to 71 years old) were enrolled at Sun Yat-sen University Cancer Center
(Guangzhou, China). During the same time period, 126 healthy volunteers (average age of 45, ranging from 19 to 75 years old) who submitted to D-dimer testing as part of a routine physical examination in our hospital were enrolled as the control group. This retrospective study was approved by the Clinical Research Ethics Committee of the Sun Yat-sen University Cancer Center, and all the participants provided written informed consent before treatment.

The routine staging patient work-up included the following clinical examinations of the head and neck region: magnetic resonance imaging scans from the suprasellar cistern to the collarbone, fibre optic nasopharyngoscopy, chest radiography, abdominal sonography, whole-body bone scan or whole body FDG PET/CT. All patients were restaged according to the seventh American Joint Committee on Cancer (AJCC) TNM staging manual. All clinical records and magnetic resonance images were independently reviewed by 2 radiologists (X.W.L and L.Z.L.) to minimise heterogeneity in restaging. Before treatment, the following baseline clinical data were collected from the medical records and information system at the study institute: sex, age, WBC counts, neutrophil counts, haemoglobin (HGB), platelet counts, LDH, CRP, hereditary NPC, smoking status, PS by Eastern Cooperative Oncology Group (ECOG), and the presence of concurrent diseases, such as cardiovascular disease, diabetes and chronic hepatitis.

\section{Treatment delivery}

One hundred and sixty-seven (23.3\%) patients were treated with conventional two-dimensional (2D-CRT) or threedimensional conformal radiotherapy (3D-CRT), and the remaining $550(76.7 \%)$ patients were treated with intensitymodulated radiotherapy (IMRT). Details of the radiotherapy techniques used at the Sun Yat-sen University Cancer Center were reported in a previous study [22,23]. Six hundred and forty (91.3\%) patients with stage II-IV disease received concurrent platinum-based chemotherapy.

A stratified multi-therapeutic protocol was used to treat patients. Radiation therapy alone was used for stage I disease, and radiation with concurrent platinum-based chemotherapy was used to treat stage II disease [24]. Concurrent chemoradiotherapy, with or without neoadjuvant or adjuvant chemotherapy, was used for advancedstage disease (stages III and IV). Neoadjuvant or adjuvant chemotherapy consisted of cisplatin with 5-fluorouracil or cisplatin with taxane administered every 3 weeks for 2 or 3 cycles [25]. The concurrent chemotherapy regimen consisted of cisplatin given on weeks 1,4 , and 7 of RT, or weekly cisplatin. All the patients at the study institution were treated according to the principle of treatment for NPC patients at Sun Yat-sen University Cancer Center, Guangzhou, China. 


\section{D-dimer evaluation}

A $3 \mathrm{~mL}$ fasting blood sample was collected before treatment of NPC patients and on the day of physical examination for the healthy volunteers. The sample was processed within 3 hours of collection, and the plasma was stored at -70 to $-80^{\circ} \mathrm{C}$ until analysis. D-dimer values were measured by a latex-enhanced immunoturbidimetric assay (Sekisui Medical Co., Ltd., Tokyo, Japan) using a Sysmex CA 7000 (Sysmex Corp., Kobe, Japan) analyser in the clinical hospital laboratory. The results were obtained using a standard curve prepared according to the manufacturer's instructions, and the inter-assay imprecision (coefficient of variation) was $<10 \%$.

\section{EBV DNA, VCA-IgA, and EA-lgA measurement}

As described in previous studies [26-28], patient plasma EBV DNA concentrations were routinely measured by q-PCR before treatment. A cut-off level of 4000 copies $/ \mathrm{ml}$ was chosen to define low and high EBV DNA levels because this threshold has previously been shown to be prognostic in NPC patients using the same measurement system [10,29]. EBV-specific VCA/IgA antibodies and EBV-specific EA/IgA antibodies were measured using a previously described immunoenzymatic assay [30].

\section{Clinical outcomes assessment and patient follow-up}

The primary endpoint of our study was disease-free survival (DFS). The secondary endpoints were distant metastasis-free survival (DMFS) and overall survival (OS). We calculated DFS from the date of the first NPC diagnosis to the date of the first relapse at any site, death from any cause or the date of the last follow-up visit. DMFS was calculated from the date of the first NPC diagnosis to the date of distant relapse or patient censoring at the date of the last follow-up. OS was calculated from the date of the first NPC diagnosis to the date of death from any cause or patient censoring at the date of the last follow-up. After treatment was completed, patients were evaluated at 3-month intervals for the first 3 years and every 6 months thereafter.

\section{Statistical analysis}

The characteristics of the patients were divided into quartiles and described by median values and the 25th75th percentiles (due to non-normally distributed continuous variables). Mann-Whitney U-tests were used to compare continuous variables in different subgroups. The Spearman correlation test was used to examine the association between D-dimer levels and other variables. Survival curves were calculated by the Kaplan-Meier method, and univariate analyses were performed using the log-rank test. Variables that reached a p-value of $\leq 0.05$ in the univariate analysis were entered into multivariate analyses. All statistical calculations were performed using SPSS 17.0 for Windows (Chicago, IL), and a $\mathrm{P}<0.05$ was considered statistically significant.

\section{Results}

Baseline characteristics and distribution of D-dimer level in the study population and subgroups

The pretreatment characteristics of the 717 NPC patients are listed in Table 1. The median follow-up was 31 months (IQR, 24-42). Forty-eight patients developed locoregional recurrences, and 85 patients developed distant metastases. Of these patients, 16 patients had both local and distant metastases. The plasma D-dimer level was higher in NPC patients than healthy volunteers $(\mathrm{P}<0.001$, Figure 1$)$, with the values of 0.50 (25th-75th percentile: $0.3-0.8)$ and $0.4 \mathrm{ug} / \mathrm{mL}$ (25th-75th percentile: $0.3-0.5)$, respectively. The median D-dimer level was higher in patients with distant metastasis compared to patients without distant metastasis $(P=0.002$, Figure 1$)$, with values of 0.60 (25th-75th percentile: $0.4-1.0$ ) and 0.50 (25th-75th percentile: $0.3-0.7)$, respectively. The D-dimer level was higher in patients with plasma EBVDNA $\geq 4000$ copies than in patients with EBVDNA $<4000$ copies $(P=0.002$, Figure 1), with values of 0.50 (25th-75th percentile: 0.3-0.9) and 0.50 (25th-75th percentile: 0.3-0.7), respectively. Patients who died during the observation period had significantly higher D-dimer levels at baseline than patients who were alive at the end of the study or the last follow-up: 0.6 (25th-75th percentile: 0.4-0.925) and 0.5 (25th-75th percentile: $0.3-0.7)$, respectively $(P=0.002$, Figure 1). A Spearman correlation analysis further demonstrated that plasma D-dimer levels correlated with age, serum CRP level, LDH level, EBV DNA level, tumour TNM stage, and distant metastasis (Additional file 1: Table S1).

\section{D-dimer levels and probability of survival}

For the Kaplan-Meier analysis, patients were categorised into the following four groups according to their D-dimer levels: the 1st group (D-dimer levels ranging from minimum to 1st quartile of D-dimer levels in the total cohort population: $0.0-0.3 \mu \mathrm{g} / \mathrm{mL}$ ), 2nd group (D-dimer levels from 1st quartile to 2 nd quartile: $0.3-0.5 \mu \mathrm{g} / \mathrm{mL}$ ), 3 rd group (D-dimer levels from 2nd quartile to 3rd quartile: $0.5-0.8 \mu \mathrm{g} / \mathrm{mL}$ ) and 4th group (D-dimer levels from 3rd quartile to maximum: $0.8-37.2 \mu \mathrm{g} / \mathrm{mL}$ ). Additional file 1 : Figure S1 shows the Kaplan-Meier estimates for DFS, DMFS and OS according to D-dimer levels. Elevated D-dimer levels were significantly associated with shorter DFS, DMFS and OS (log-rank trend test: $\mathrm{P}<0.001$ ).

Using the 1st group as a reference, the unadjusted hazard ratio (HR) for DFS, DMFS, and OS of the top quartiles were 2.26 (95\% CI, 1.38-3.70), 2.99 (95\% CI, 1.63-5.48), and 3.06 (95\% CI, 1.70-5.51), respectively. A similar trend of adjusted HR was observed for DFS, 
Table 1 Patient demographics and clinical characteristics Characteristic

$\begin{array}{lr}\text { Characteristic } & \begin{array}{c}\text { Median (25th-7 } \\ \text { percentile) } \\ \text { No. (\%) }\end{array} \\ \text { NPC patients (n }= \\ \text { Age at study entry } & 47(39-47) \\ \text { Sex } & \\ \text { Male } & 533(74.3) \\ \text { Female } & 184(25.7) \\ \text { D-dimer } & \text { ug/mL (0.3 } \\ \text { Histology, WHO type } & \\ \text { III } & 690(96.2) \\ \text { II } & 27(3.8) \\ \text { ECOG } & \\ \text { 0-1 } & 712(99.3) \\ 2 & 5(0.7) \\ \text { Clinical stage } & \\ \text { I } & 16(2.2) \\ \text { II } & 80(11.2) \\ \text { III } & 416(58.0) \\ \text { IV } & 205(28.6) \\ \text { Tumour stage } & \\ \text { T1 } & 54(7.5) \\ \text { T2 } & 128(17.9) \\ \text { T3 } & 367(51.2) \\ \text { T4 } & 168(23.4) \\ \text { Node sta }\end{array}$

Node stage

$\begin{array}{lc}\text { No } & 112(15.6) \\ \text { N1 } & 273(38.1) \\ \text { N2 } & 277(38.6) \\ \text { N3 } & 55(7.7)\end{array}$

Treatment

$\begin{array}{lc}\text { Radiotherapy } & 75(10.5) \\ \begin{array}{l}\text { Chemotherapy and } \\ \text { radiotherapy }\end{array} & 642(89.5) \\ \text { Radiotherapy technique } & \\ \text { 2DRT/3DCRT } & 167(23.3) \\ \text { IMRT } & 550(76.7) \\ \text { EBVDNA } & \\ \text { Low DNA } & 411(57.3) \\ \text { High DNA } & 306(42.7) \\ \text { VCA-IgA } & \\ <1: 80 & 223(31.1) \\ \geq 1: 80 & 494(68.9) \\ \text { EA-IgA } & \\ <1: 10 & 315(43.9)\end{array}$

Table 1 Patient demographics and clinical characteristics (Continued)

$\geq 1: 10 \quad 402(56.1)$

$\mathrm{LDH}, \mathrm{U} / \mathrm{L}$

$\begin{array}{cc}<167 & 353(49.2) \\ \geq 167 & 364(50.8) \\ \text { CRP, mg/L } & \\ <1.61 & 359(50.1) \\ \geq 1.61 & 358(49.9)\end{array}$

WBC, 109/L

$\begin{array}{ll}<6.7 & 362(50.5) \\ \geq 6.7 & 355(49.5)\end{array}$

Neutrophil, 109/L

$\begin{array}{ll}<4.0 & 359(50.2) \\ \geq 4.0 & 358(49.8)\end{array}$

HGB, g/L

$\begin{array}{ll}<143.8 & 359(50.1) \\ \geq 143.8 & 358(49.9)\end{array}$

PLT, 109/L

$<227 \quad 359(50.1)$

$\geq 227 \quad 358(49.9)$

Smoking

yes $\quad 259(63.9)$

no $\quad 458$ (36.1)

Chronic HBV Infection

yes $\quad 57(7.9)$

no $\quad 660(92.1)$

Cardiovascular disease

$\begin{array}{lc}\text { yes } & 61(8.5) \\ \text { no } & 656(91.5)\end{array}$

Diabetes mellitus

$\begin{array}{cc}\text { yes } & 22(3.1) \\ \text { no } & 695(96.9)\end{array}$

Family history of NPC

$\begin{array}{lc}\text { yes } & 61(8.5) \\ \text { no } & 656(91.5) \\ \begin{array}{l}\text { Median follow-up } \\ \text { (months) }\end{array} & 31(24-44)\end{array}$

Outcome features

Progression

$\begin{array}{ll}\text { yes } & 118(16.5) \\ \text { no } & 599(83.5)\end{array}$

Distant metastasis

$\begin{array}{ll}\text { yes } & 85(11.9) \\ \text { no } & 632(88.1)\end{array}$


Table 1 Patient demographics and clinical characteristics (Continued)

\begin{tabular}{lc}
\hline Localregional recurrence & \\
yes & $48(6.7)$ \\
no & $669(93.3)$ \\
Deaths & \\
yes & $94(13.1)$ \\
no & $623(86.9)$
\end{tabular}

Abbreviations: ECOG Eastern Cooperative Oncology Group, 2DRT twodimensional radiotherapy, 3DCRT three-dimensional conformal radiotherapy, IMRT intensity-modulated radiotherapy, Low DNA denotes a low EBV DNA level of $<4000$ copies $/ \mathrm{ml}$, High DNA denotes a high EBV DNA level of $\geq 4000$ copies/ml, VCA viral capsid antigen. IgA immunoglobulin A, EA early antigen, $L D H$ Serum Lactate Dehydrogenase Levels, CRP high-sensitivity C-reactive protein, WBC White blood cell, HGB haemoglobin, PLT platelet, NPC nasopharyngeal carcinoma.

DMFS and OS. HRs and 95\% CIs comparing quartiles of D-dimer for disease-free, distant metastasis and overall survival are detailed in Additional file 1: Table S2. The patients were divided into two groups based on whether the D-dimer level was above or below the top quartiles $(0.8 \mu \mathrm{g} / \mathrm{L})$. Patients with high D-dimer levels had a shorter 3-year DFS, (79\%, 95\%CI (73.1-84.9)) vs. (69\%, 95\%CI (59.2-78.8)), DMFS (87\%, 95\%CI (83.1-90.9)) vs. (77\%, 95\%CI (69.2-84.8)), and overall survival (82\%, 95\% CI (76.1-87.9)) vs. (76\%, 95\%CI (66.2-85.8)) (Figure 2).
Univariate and multivariate analyses of prognostic factors As shown in Table 2, using $0.8 \mathrm{ug} / \mathrm{L}$ as a cut-off value, the hazard ratios (HRs) and 95\% CIs estimated from Cox regression models indicated that the $\mathrm{D}$-dimer level was strongly associated with DFS, DMFS, and OS (HR, 1.88; 95\% CI, 1.28 to 2.77 ), (HR, 2.16; 95\%CI, 1.38 to 3.36 ) and (HR, 1.98; 95\%CI, 1.29 to 3.04 ), respectively. In addition to elevated D-dimer levels, the UICC TNM classification, high EBV DNA and elevated CRP levels (1.61 mg/L) were significantly associated with DFS, DMFS, and OS.

Multivariate analysis indicated that elevated D-dimer levels were a highly significant predictor for DFS, DMFS, and OS, independent of EBV DNA level, LDH level, CRP levels, UICC TNM staging, smoking status, and treatment type (Table 3).

\section{Prognostic significance of D-dimer within the UICC TNM} classification, and patients with high or low EBVDNA level Given the independent prognostic significance of elevated D-dimer levels in NPC patients, we evaluated the discrimination power of elevated D-dimer levels in early-stage and advanced-stage patients. Compared to patients with low D-dimer levels, patients with earlystage and advanced-stage disease with elevated D-dimer levels had shorter DFS, DMFS, and OS (Figure 3).

Consistent with previous reports [10,29], we chose 4000 copies $/ \mathrm{ml}$ to define the low and high pre-treatment
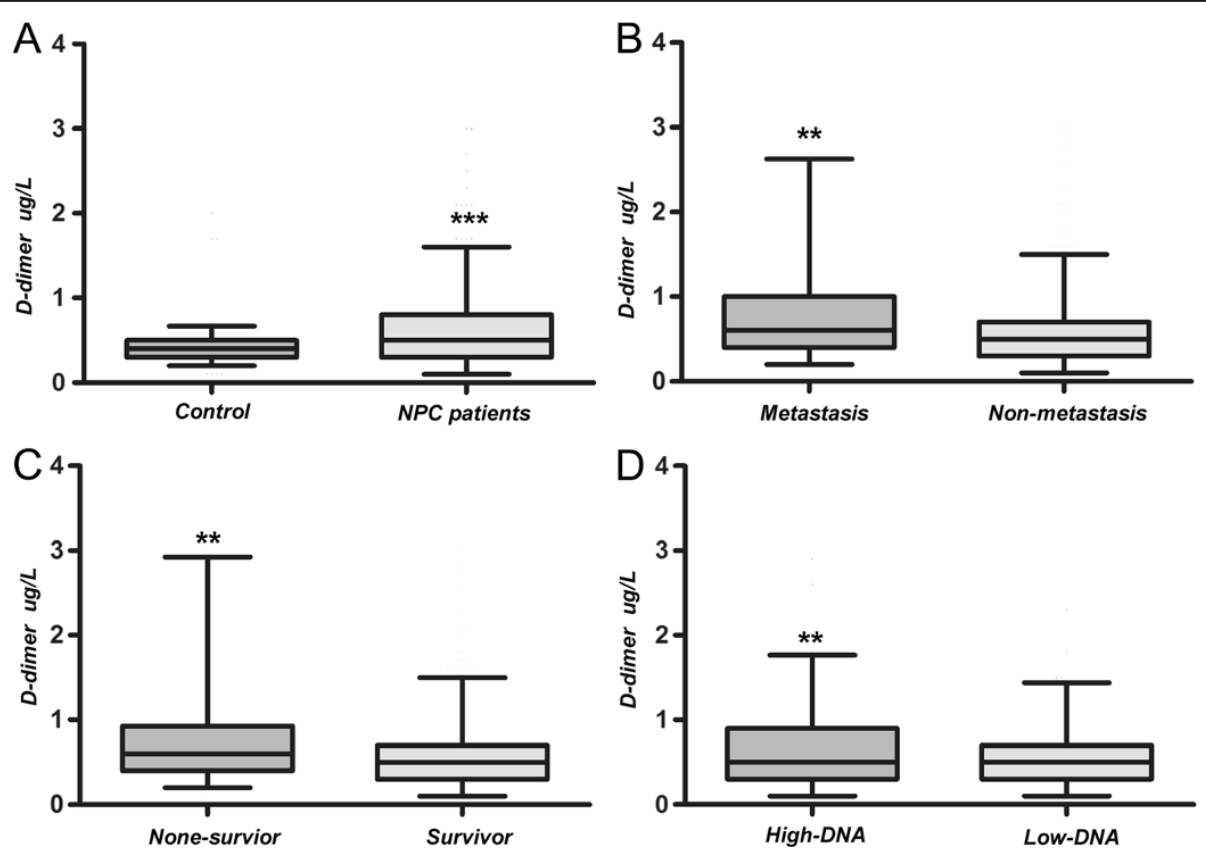

Figure 1 Plasma D-dimer levels are expressed as the median and 5\%-95\% percentile in patients with nasopharyngeal carcinoma according to different variables. (A) Healthy volunteers versus nasopharyngeal carcinoma patients; (B) Nasopharyngeal carcinoma with distant metastasis after treatment versus non-distant metastasis ( $P=0.002)$; (C) Non-survivors versus survivors ( $P=0.002)$; (D) High DNA ( $\geq 4000$ copies/ml) versus low DNA ( $<4000$ copies $/ \mathrm{ml})(P=0.002)$. 


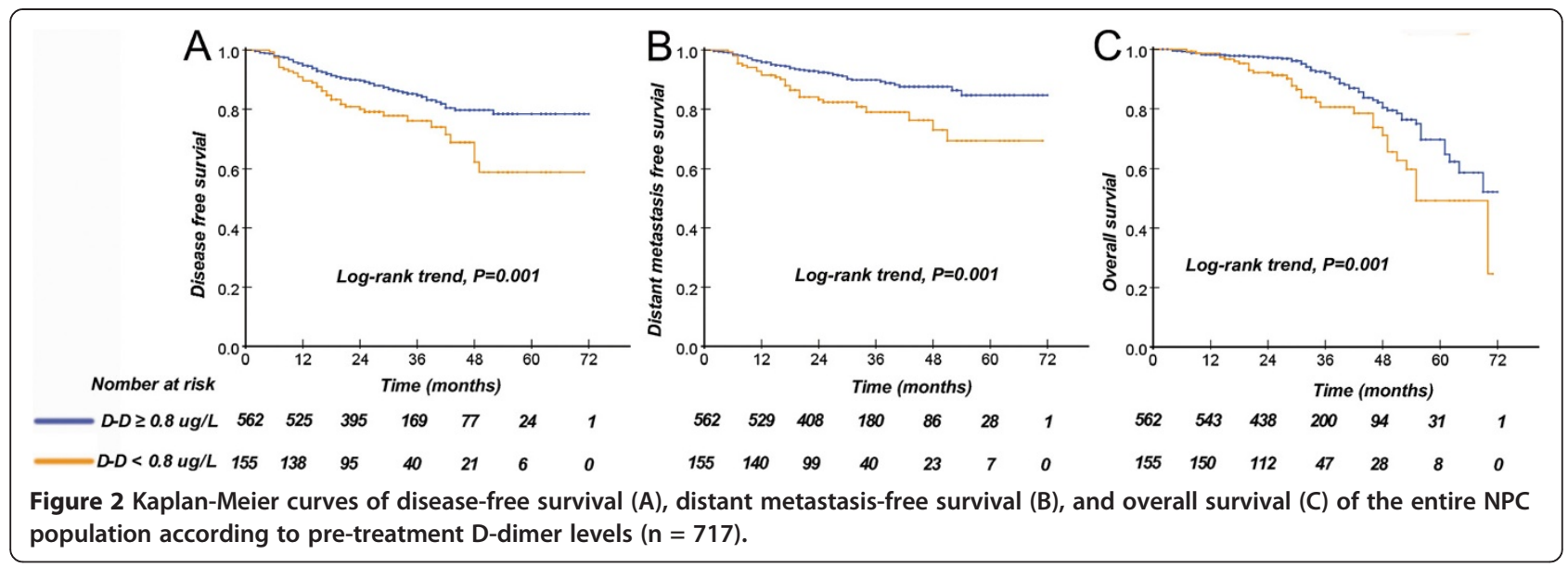

Table 2 Univariate Cox proportional hazards regression analysis

\begin{tabular}{|c|c|c|c|c|c|c|c|c|c|}
\hline \multirow[t]{2}{*}{ Characteristic } & \multicolumn{3}{|c|}{ DFS $(n=717)$} & \multicolumn{3}{|c|}{ DMFS $(n=717)$} & \multicolumn{3}{|c|}{ OS $(n=717)$} \\
\hline & HR & $95 \% \mathrm{Cl}$ & $P$ & HR & $95 \% \mathrm{Cl}$ & $P$ & HR & $95 \% \mathrm{Cl}$ & $P$ \\
\hline Age, ( $\geq 47$ vs. $<47$ years) & 0.73 & 0.51 to 1.06 & 0.100 & 0.87 & 0.56 to 1.33 & 0.517 & 0.85 & 0.56 to 1.29 & 0.444 \\
\hline Male vs. Female & 1.08 & 0.71 to 1.65 & 0.726 & 1.48 & 0.86 to 2.54 & 0.162 & 0.92 & 0.64 to 1.65 & 0.922 \\
\hline Histology, WHO type (III vs. II) & 0.95 & 0.42 to 2.53 & 0.949 & 0.69 & 0.28 to 1.70 & 0.689 & 1.78 & 0.56 to 5.62 & 0.328 \\
\hline ECOG (2 vs. 0-1) & 1.10 & 0.15 to 7.85 & 0.927 & 1.05 & 0.36 to 6.53 & 0.596 & 1.25 & 0.14 to 8.99 & 0.824 \\
\hline Clinical stage (III-IV) vs. (I-II) & 3.05 & 1.34 to 6.94 & 0.008 & 4.43 & 1.40 to 14.01 & 0.011 & 2.56 & 1.04 to 6.31 & 0.041 \\
\hline Tumour stage (T3-4 vs. T1-2) & 1.47 & 0.93 to 2.31 & 0.100 & 1.65 & 0.94 to 2.88 & 0.08 & 1.32 & 0.80 to 2.18 & 0.286 \\
\hline Node stage (N2-3 vs. N0-1) & 1.72 & 1.19 to 2.48 & 0.004 & 2.19 & 1.40 to 3.42 & 0.001 & 1.75 & 1.16 to 2.66 & 0.008 \\
\hline Chemoradiotherapy (yes v no) & 1.94 & 0.90 to 4.17 & 0.089 & 1.58 & 0.69 to 3.63 & 0.279 & 1.59 & 0.70 to 3.64 & 0.27 \\
\hline IMRT vs. 2DRT/3DCRT & 0.55 & 0.38 to 0.80 & 0.002 & 0.66 & 0.42 to 1.04 & 0.071 & 0.88 & 0.57 to 1.34 & 0.537 \\
\hline High DNA Vs. Low DNA & 2.97 & 2.02 to 4.36 & $<0.001$ & 3.69 & 2.30 to 5.91 & $<0.001$ & 3.50 & 2.23 to 5.50 & $<0.001$ \\
\hline CRP, mg/L $(\geq 1.61 \mathrm{vs} .<1.61)$ & 1.43 & 0.99 to 2.06 & 0.055 & 1.83 & 1.18 to 2.84 & 0.007 & 1.87 & 1.23 to 2.85 & 0.003 \\
\hline VCA-lgA ( $\geq 1: 80$ vs. $<1: 80)$ & 1.39 & 0.91 to 2.13 & 0.127 & 1.32 & 0.81 to 2.16 & 0.267 & 0.95 & 0.64 to 1.61 & 0.952 \\
\hline EA-lgA ( $\geq 1: 10$ vs. $<1: 10)$ & 1.23 & 0.85 to 1.77 & 0.282 & 1.17 & 0.76 to 1.81 & 0.477 & 0.99 & 0.66 to 1.50 & 0.977 \\
\hline LDH, U/L ( $\geq 167$ vs. $<167)$ & 1.41 & 0.98 to 2.04 & 0.064 & 1.67 & 1.07 to 2.59 & 0.002 & 1.38 & 0.92 to 2.08 & 0.125 \\
\hline D-dimer, ug/L ( $\geq 0.8$ vs. $<0.8)$ & 1.88 & 1.28 to 2.77 & 0.001 & 2.16 & 1.38 to 3.36 & 0.001 & 1.98 & 1.29 to 3.04 & 0.002 \\
\hline WBC, $109 / \mathrm{L}(\geq 6.7$ vs. $<6.7)$ & 1.06 & 0.90 to 1.25 & 0.753 & 1.17 & 0.76 to 1.9 & 0.481 & 1.08 & 0.72 to 1.62 & 0.709 \\
\hline Neutrophil, 109/L ( $\geq 4.1$ vs. < 4.1) & 1.09 & 0.76 to 1.56 & 0.658 & 1.03 & 0.67 to 1.57 & 0.9 & 1.24 & 0.82 to 1.87 & 0.308 \\
\hline HGB, g/l ( $\geq 143.8$ vs. $<143.8)$ & 0.87 & 0.61 to 1.25 & 0.463 & 0.82 & 0.53 to 1.25 & 0.35 & 0.77 & 0.51 to 1.16 & 0.207 \\
\hline PLT, 109/L ( $\geq 227$ vs. $<227)$ & 1.13 & 0.79 to 1.62 & 0.511 & 1.08 & 0.71 to 1.66 & 0.712 & 1.23 & 0.82 to 1.84 & 0.33 \\
\hline Smoking (yes vs. no) & 1.27 & 0.88 to 1.84 & 0.196 & 1.59 & 1.04 to 2.44 & 0.033 & 1.22 & 0.81 to 1.84 & 0.346 \\
\hline Chronic HBV Infection (yes vs. no) & 1.00 & 0.84 to 1.18 & 0.953 & 1.02 & 0.84 to 1.23 & 0.881 & 0.97 & 0.80 to 1.18 & 0.969 \\
\hline cardiovascular disease (yes $\vee$ no) & 1.16 & 0.61 to 2.22 & 0.653 & 1.28 & 0.62 to 2.67 & 0.5 & 1.64 & 0.79 to 3.41 & 0.184 \\
\hline Diabetes mellitus (yes v no) & 0.94 & 0.85 to 1.05 & 0.286 & 0.97 & 0.87 to 1.08 & 0.592 & 0.94 & 0.84 to 1.05 & 0.248 \\
\hline family history of NPC (yes $\vee$ no) & 1.14 & 0.61 to 2.11 & 0.686 & 1.13 & 0.55 to 2.35 & 0.735 & 1.14 & 0.92 to 1.41 & 0.241 \\
\hline
\end{tabular}

Abbreviations: ECOG Eastern Cooperative Oncology Group, 2DRT two-dimensional radiotherapy, 3DCRT three-dimensional conformal radiotherapy, IMRT intensity-modulated radiotherapy, Low DNA denotes a low EBV DNA level of $<4000$ copies/ml, High DNA denotes a high EBV DNA level of $\geq 4000$ copies/ml, $V C A$ viral capsid antigen. IgA immunoglobulin $\mathrm{A}, E A$ early antigen, $L D H$ Serum Lactate Dehydrogenase Levels, CRP high-sensitivity C-reactive protein, WBC White blood cell, HGB haemoglobin, PLT platelet, NPC nasopharyngeal carcinoma. DFS disease-free survival, DMFS metastasis-free survival, OS overall survival. 
Table 3 Multivariate Cox proportional hazards regression analysis

\begin{tabular}{|c|c|c|c|c|c|c|c|c|c|}
\hline \multirow[t]{2}{*}{ Characteristic } & \multicolumn{3}{|c|}{ DFS $(n=717)$} & \multicolumn{3}{|c|}{ DMFS $(n=717)$} & \multicolumn{3}{|c|}{ OS $(n=717)$} \\
\hline & $\mathrm{HR}$ & $95 \% \mathrm{Cl}$ & $P$ & HR & $95 \% \mathrm{Cl}$ & $P$ & $\mathrm{HR}$ & $95 \% \mathrm{Cl}$ & $P$ \\
\hline Tumour stage (T3-4 vs. T1-2) & 1.23 & 0.76 to 1.99 & 0.395 & 1.36 & 0.76 to 2.45 & 0.305 & 1.04 & 0.61 to 1.79 & 0.88 \\
\hline Node stage (N2-3 vs. N0-1) & 1.14 & 0.76 to 1.71 & 0.516 & 1.43 & 0.88 to 2.33 & 0.148 & 1.08 & 0.68 to 1.72 & 0.756 \\
\hline Chemoradiotherapy (yes vs. no) & 1.23 & 0.55 to 2.74 & 0.621 & 0.84 & 0.40 to 2.02 & 0.7 & 0.89 & 0.36 to 2.18 & 0.793 \\
\hline IMRT vs. 2DRT/3DCRT & 0.62 & 0.42 to 0.90 & 0.013 & 0.76 & 0.48 to 1.21 & 0.246 & 0.99 & 0.64 to 1.52 & 0.954 \\
\hline High DNA vs. Low DNA & 2.41 & 1.59 to 3.64 & $<0.001$ & 2.77 & 1.66 to 4.62 & $<0.001$ & 3.06 & 1.87 to 5.02 & $<0.001$ \\
\hline$C R P, m g / L(\geq 1.61$ vs. $<1.61)$ & 1.14 & 0.78 to 1.68 & 0.495 & 1.35 & 0.85 to 2.14 & 0.21 & 1.48 & 0.95 to 231 & 0.082 \\
\hline LDH, U/L ( $\geq 167$ vs. $<167)$ & 1.22 & 0.84 to 1.77 & 0.290 & 1.35 & 0.86 to 2.11 & 0.189 & 1.23 & 0.81 to 1.86 & 0.34 \\
\hline D-dimer, ug/L ( $\geq 0.8$ vs. $<0.8)$ & 1.60 & 1.08 to 2.37 & 0.020 & 1.79 & 1.13 to 2.82 & 0.013 & 1.58 & 1.02 to 2.45 & 0.043 \\
\hline Smoking (yes vs. no) & 1.26 & 0.87 to 1.82 & 0.216 & 1.58 & 1.03 to 2.43 & 0.036 & 1.35 & 0.89 to 2.06 & 0.159 \\
\hline
\end{tabular}

Abbreviations: ECOG Eastern Cooperative Oncology Group, 2DRT two-dimensional radiotherapy, 3DCRT three-dimensional conformal radiotherapy, IMRT intensity-modulated radiotherapy, Low DNA denotes a low EBV DNA level of $<4000 \mathrm{copies} / \mathrm{ml}$, High DNA denotes a high EBV DNA level of $\geq 4000$ copies/ml, LDH Serum Lactate Dehydrogenase Levels, CRP high-sensitivity C-reactive protein, DFS disease-free survival, DMFS metastasis-free survival, OS overall survival.

EBVDNA level. In subgroup analysis, patients in the high EBV DNA subgroup with elevated D-dimer levels had a worse DFS, DMFS, and OS compared with the patients with low D-dimer levels. For patients with low EBV DNA levels, there was no difference in DFS, DMFS, and OS between the patients with low or high D-dimer levels (Figure 4).

\section{Discussion}

To our knowledge, this is the first large-scale cohort study examining the association between coagulation and survival in nasopharyngeal carcinoma patients. The activation of coagulation in cancer patients is widely implicated in both tumour progression and the development of thrombosis [31]. High levels of plasma D-dimer

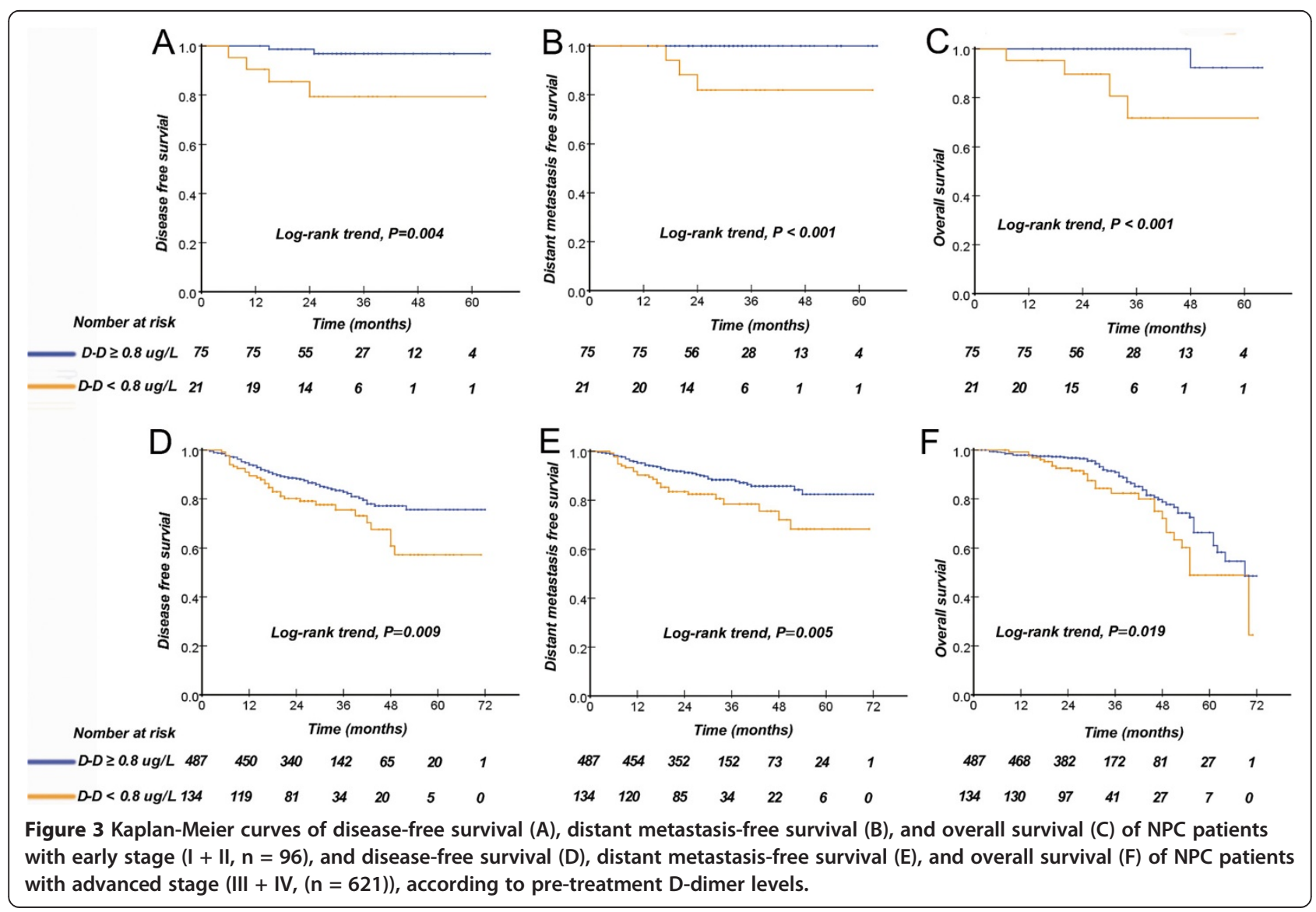




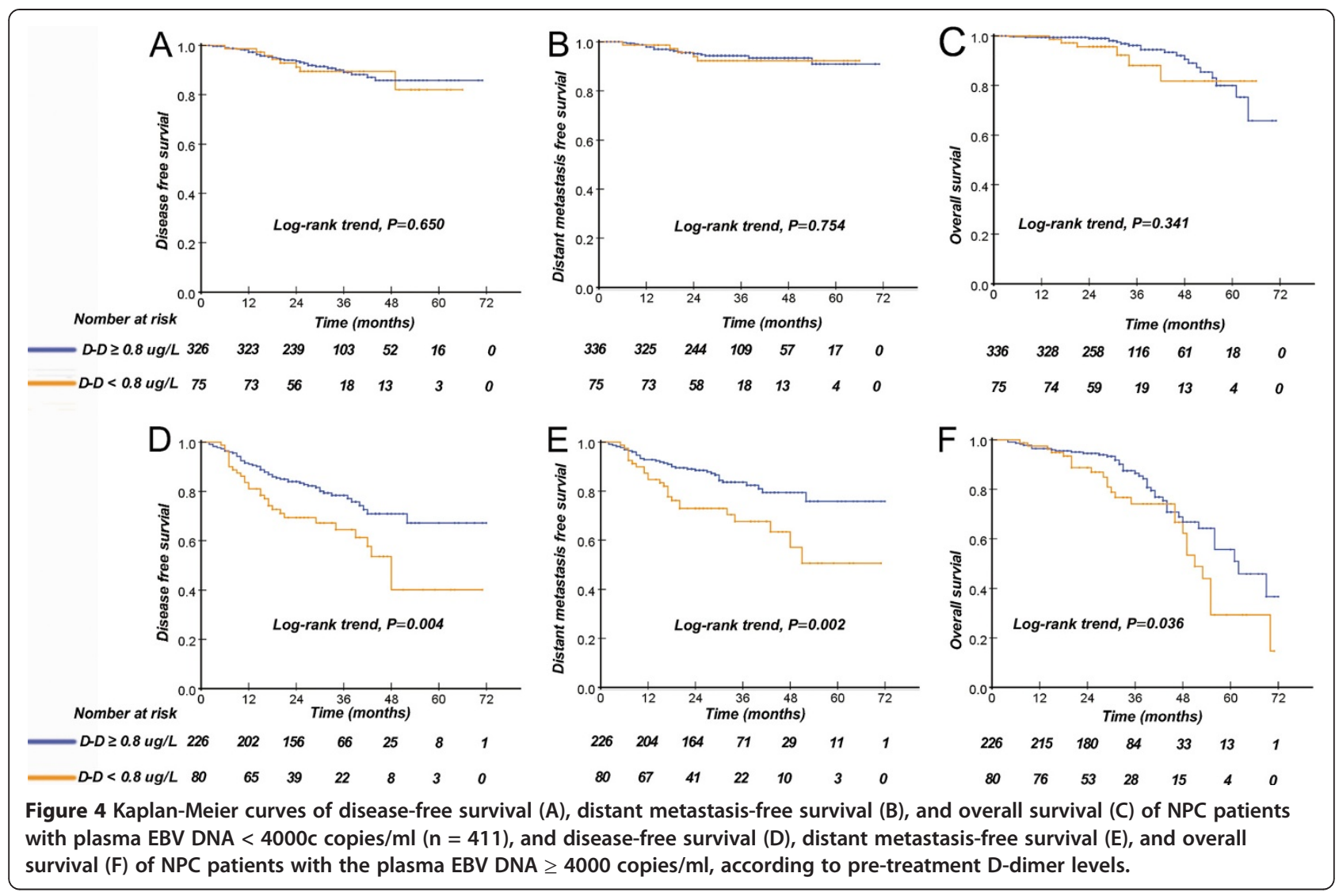

have been associated with poor prognosis in several malignant diseases, including lung pancreas, prostate, gastric, colorectal, and breast cancer [19,20,32,33]. Recently, Liu et al. [32] demonstrated that elevated plasma D-dimer was correlated with depth of invasion, lymph node metastasis, peritoneal dissemination, distant metastasis, tumour size, TNM stage, and worse overall survival in gastric cancer. Interestingly, according to our findings, the D-dimer plasma level is a marker of endogenous fibrinolysis that can be used to evaluate hypercoagulability, and it has both clinical and prognostic significance in nasopharyngeal carcinoma patients. With a median follow-up of 3 years, the HR of DFS, DMFS, and OS in cancer patients with the highest D-dimer levels in the total study population (D-dimer levels ranging from 3rd quartile to the maximum level) was two-fold higher than patients with $\mathrm{D}$-dimer levels ranging from the minimum to the 1st quartile. Using the 3rd quartile $(0.8 \mu \mathrm{g} / \mathrm{mL})$ as the final cut-off, multivariate analysis revealed that pre-treatment D-dimer levels were a significant, independent prognostic factor for predicting recurrence, distant metastasis, and death. This effect was independent of EBV DNA level, LDH level, CRP levels, UICC TNM staging, smoking status, and treatment type (Table 3).
Plasma EBV DNA has been demonstrated to be correlated with tumour burden [34], TNM stage [35], response to chemoradiotherapy [36-38], and survival in NPC patients $[8,10,29]$. Plasma EBV DNA is now a useful biomaker for the clinical management of NPC patients, and it is considered the most attractive potential biomarker [37]. However, for NPC patients with EBV DNA $\geq 4000$ copies/ml, patients with D-dimer $\geq 0.8 \mu \mathrm{g} / \mathrm{L}$ still have a shorter DFS, DMFS, and OS compared to patients with D-dimer $<0.8 \mu \mathrm{g} / \mathrm{L}$. However, this result does not apply to patients with EBV DNA $<4000$ copies $/ \mathrm{ml}$. Although the magnitude of the predictive value of EBV DNA was superior to that of D-dimer, it is not sufficient to use plasma EBV DNA alone for prognostic stratification due to the heterogeneity of NPC patients. Notably, patients in the high EBV DNA subgroup with high plasma D-dimer levels had a worse disease-free survival, distant metastasis-free survival, and overall survival. These results indicate that EBV DNA alone is insufficient to complement the TNM classification, and plasma D-dimer levels represent a complementary marker to EBV DNA leves for the prediction of NPC patient prognosis.

Although the mechanism underlying D-dimer-mediated NPC progression of remains unknown, it is likely due to different D-dimer signalling pathways or biological 
behaviours. The association between the D-dimer levels and NPC progression may be explained by abnormalities in haemostasis and fibrinolysis during tumour pathogenesis. The activation of coagulation is the result of increased tissue factor expression, which leads to fibrin deposition. Tumour cells also express tissue factors, and they might contribute to a variety of pathological processes, such as VTE, metastatic spread, tumour growth, and tumour angiogenesis [39].

Interestingly, elevated D-dimer levels still predicted a poorer DFS, DMFS, and OS for early and advanced stage NPC patients in both high and low EBV DNA subgroups, independent of TNM staging (Figure 3). Recent advancements in NPC patient classification and NPC molecular alterations have been made, including microRNA signatures [40] and the NPC-SVM classifier [41]. However, these developments require expensive and complicated procedures, and rapid clinical implementation was difficult to achieve in a short time. Plasma D-dimer levels are established, routinely measured bloodbased parameters that are reproducibly detected without additional laborious efforts before use in clinical applications. These findings have great clinical relevance because D-dimer subgroups with different prognoses in defined TNM stages indicate the need for individual treatment for NPC patients in the future. The association between pretreatment D-dimer levels and TNM stage may be helpful for screening NPC patients. If a patient displays an abnormally high D-dimer level before treatment, they may require more intensive systemic approaches to improve the treatment outcome.

However, there are still some limitations to the present study, such as the single D-dimer measurements recorded from a single centre. Another limitation of this study is that we neglected to collect data for venous thromboembolism (VTE) events. High D-dimer levels have previously been reported to predict VTE in cancer patients $[42,43]$, and both D-dimer and VTE are negative prognostic factors for cancer patients [33]. The third limitation was the short follow-up time, and additional patient data will be reported after the the 5 year follow-up.

\section{Conclusions}

In summary, we demonstrated that pre-treatment D-dimer levels can reflect hypercoagulability in NPC patients. Our results suggest that D-dimer is a promising prognostic biomarker associated with disease-free, distant metastasis-free and overall survival. D-dimers represent a widely available potential biomarker, and the assays to detect D-dimer levels have been sufficiently validated. $\mathrm{D}$-dimers should be considered for routine testing in NPC patients. A prospective study is needed to explore this area, and our results should be validated using other datasets.

\section{Additional file}

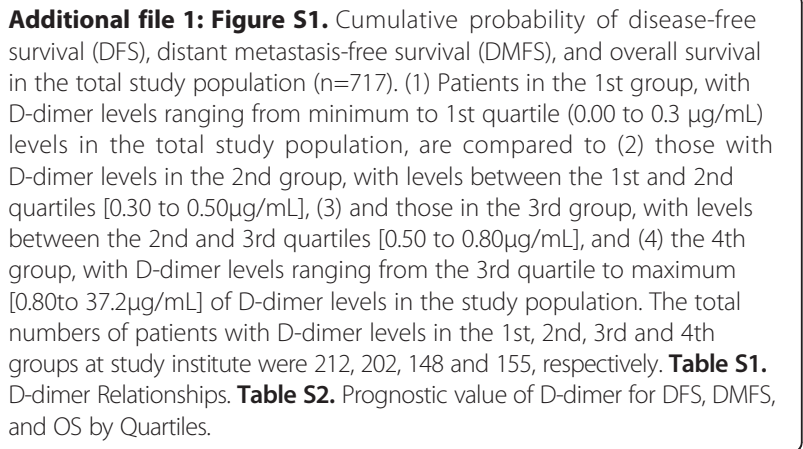

\section{Competing interests}

We declare that the authors have no competing interest.

\section{Authors' contributions}

W-HC and L-QT participated in the experimental work, literature research, study design, data collection, data analysis, interpretation of findings and the drafting of the manuscript. F-WW, C-PL, X-PT, X-XH, S-J M, Y-JL, H-XD, Q-YC, $H L$, LZ, S-SG, L-TL, J-PZ and S-MY collected blood samples, patient materials and patient follow-up information. $X-W L, L-Z L$ reviewed MR images. C-FL and QL performed statistical analyses. H-QM, M-SZ and DX conceived of and coordinated the study, and critically revised the manuscript. All authors read and approved the final manuscript.

\section{Acknowledgments}

We are grateful to the patients who participated in this study. This study was supported by grants from the Nature Science Foundation of China (No. 81225018, 81172340, 81172939, 81201629 and 81072226), the 863 Project (No: 2012AA02A501), the National Key Basic Research Program of China (No: 2013CB910304), the Sci-Tech Project Foundation of Guangdong Province (No: 2011B080701034, and 2011B031800161), and the Sci-Tech Project Foundation of Guangzhou City (No: 2011 J4300100).

\section{Author details}

${ }^{1}$ Sun Yat-sen University Cancer Center, State Key Laboratory of Oncology in South China; Collaborative Innovation Centre for Cancer Medicine, Guangzhou 510060, P. R. China. ²Department of Nasopharyngeal Carcinoma, Sun Yat-sen University Cancer Center, Guangzhou 510060, P. R. China. ${ }^{3}$ Department of Pathology, Sun Yat-sen University Cancer Center, Guangzhou 510060, P. R. China. ${ }^{4}$ Department of Information Technology, Sun Yat-sen University Cancer Center, Guangzhou 510060, P. R. China. ${ }^{5}$ Department of Clinical Laboratory, Sun Yat-sen University Cancer Center, Guangzhou 510060, P. R. China. 'Department of Statistics and Epidemiology, Sun Yat-sen University Cancer Center, Guangzhou 510060, P. R. China. ${ }^{7}$ Imaging Diagnostic and Interventional Centre, Sun Yat-sen University Cancer Center, Guangzhou 510060, P. R. China.

Received: 6 May 2014 Accepted: 30 July 2014 Published: 10 August 2014

\section{References}

1. Wee $\mathrm{JT}, \mathrm{Ha} \mathrm{TC}$, Loong $\mathrm{SL}$, Qian CN: Is nasopharyngeal cancer really a "Cantonese cancer"? Chin J Cancer 2010, 29(5):517-526.

2. Chang ET, Adami HO: The enigmatic epidemiology of nasopharyngeal carcinoma. Cancer Epidemiol Biomarkers Prev 2006, 15(10):1765-1777.

3. Jemal A, Bray F, Center MM, Ferlay J, Ward E, Forman D: Global cancer statistics. CA Cancer J Clin 2011, 61(2):69-90.

4. Tatsumi-Tamori A, Yoshizaki T, Miwa T, Furukawa M: Clinical evaluation of staging system for nasopharyngeal carcinoma: comparison of fourth and fifth editions of UICC TNM classification. Ann Otol Rhinol Laryngol 2000, 109(12 Pt 1):1125-1129.

5. Chua DT, Nicholls JM, Sham JS, Au GK: Prognostic value of epidermal growth factor receptor expression in patients with advanced stage 
nasopharyngeal carcinoma treated with induction chemotherapy and radiotherapy. Int J Radiat Oncol Biol Phys 2004, 59(1):11-20.

6. Zhou GQ, Tang LL, Mao YP, Chen L, Li WF, Sun Y, Liu LZ, Li L, Lin AH, Ma J: Baseline serum lactate dehydrogenase levels for patients treated with intensity-modulated radiotherapy for nasopharyngeal carcinoma: a predictor of poor prognosis and subsequent liver metastasis. Int J Radiat Oncol Biol Phys 2012, 82(3):e359-e365

7. Xia WX, Zhang HB, Shi JL, Lu X, Wang L, Ye YF, Cao KJ, Qian CN, Guo X, Xiang YQ: A prognostic model predicts the risk of distant metastasis and death for patients with nasopharyngeal carcinoma based on pre-treatment serum $\mathrm{C}$-reactive protein and N-classification. Eur J Cancer 2013, 49(9):2152-2160.

8. Lin JC, Wang WY, Chen KY, Wei YH, Liang WM, Jan JS, Jiang RS: Quantification of plasma Epstein-Barr virus DNA in patients with advanced nasopharyngeal carcinoma. N Engl J Med 2004, 350(24):2461-2470.

9. Leung SF, Chan AT, Zee B, Ma B, Chan LY, Johnson PJ, Lo YM: Pretherapy quantitative measurement of circulating Epstein-Barr virus DNA is predictive of posttherapy distant failure in patients with early-stage nasopharyngeal carcinoma of undifferentiated type. Cancer 2003, 98(2):288-291.

10. Leung SF, Zee B, Ma BB, Hui EP, Mo F, Lai M, Chan KC, Chan LY, Kwan WH, Lo YM, Chan AT: Plasma Epstein-Barr viral deoxyribonucleic acid quantitation complements tumor-node-metastasis staging prognostication in nasopharyngeal carcinoma. J Clin Oncol 2006, 24(34):5414-5418.

11. Lyman $\mathrm{GH}$, Khorana $\mathrm{AA}$ : Cancer, clots and consensus: new understanding of an old problem. J Clin Oncol 2009, 27(29):4821-4826.

12. Beer JH, Haeberli A, Vogt A, Woodtli K, Henkel E, Furrer T, Fey MF: Coagulation markers predict survival in cancer patients. Thromb Haemost 2002, 88(5):745-749.

13. Edwards RL, Rickles FR, Moritz TE, Henderson WG, Zacharski LR, Forman WB, Cornell CJ, Forcier RJ, O'Donnell JF, Headley E: Abnormalities of blood coagulation tests in patients with cancer. Am J Clin Pathol 1987, 88(5):596-602.

14. Falanga A, Panova-Noeva M, Russo L: Procoagulant mechanisms in tumour cells. Best Pract Res Clin Haematol 2009, 22(1):49-60.

15. Lippi G, Franchini M, Biasiutti C, Dellagiacoma G, Salvagno GL, Guidi GC: Increased D-dimer value and occult cancer in the absence of detectable thrombosis. Haematologica 2007, 92(4):e53-e55.

16. Murray JC: Coagulation and cancer. Br J Cancer 1991, 64(3):422-424.

17. Alcalay A, Wun T, Khatri V, Chew HK, Harvey D, Zhou H, White RH: Venous thromboembolism in patients with colorectal cancer: incidence and effect on survival. J Clin Oncol 2006, 24(7):1112-1118.

18. Batschauer AP, Figueiredo CP, Bueno EC, Ribeiro MA, Dusse LM, Fernandes AP, Gomes KB, Carvalho MG: D-dimer as a possible prognostic marker of operable hormone receptor-negative breast cancer. Ann Oncol 2010, 21(6):1267-1272.

19. Blackwell K, Hurwitz H, Lieberman G, Novotny W, Snyder S, Dewhirst M, Greenberg C: Circulating D-dimer levels are better predictors of overall survival and disease progression than carcinoembryonic antigen levels in patients with metastatic colorectal carcinoma. Cancer 2004 101(1):77-82.

20. Buccheri $G$, Torchio $P$, Ferrigno D: Plasma levels of D-dimer in lung carcinoma: clinical and prognostic significance. Cancer 2003, 97(12):3044-3052.

21. Nakashima J, Tachibana M, Ueno M, Baba S, Tazaki H: Tumor necrosis factor and coagulopathy in patients with prostate cancer. Cancer Res 1995, 55(21):4881-4885.

22. Zhao C, Han F, Lu LX, Huang SM, Lin CG, Deng XW, Lu TX, Cui NJ: [Intensity modulated radiotherapy for local-regional advanced nasopharyngeal carcinoma]. Ai Zheng 2004, 23(11 Suppl):1532-1537.

23. Ma J, Liu L, Tang L, Zong J, Lin A, Lu T, Cui N, Cui C, Li L: Retropharyngeal lymph node metastasis in nasopharyngeal carcinoma: prognostic value and staging categories. Clin Cancer Res 2007, 13(5):1445-1452.

24. Chen QY, Wen YF, Guo L, Liu H, Huang PY, Mo HY, Li NW, Xiang YQ, Luo DH, Qiu F, Sun R, Deng MQ, Chen MY, Hua YJ, Guo X, Cao KJ, Hong MH, Qian CN, Mai $\mathrm{HQ}$ : Concurrent chemoradiotherapy vs radiotherapy alone in stage II nasopharyngeal carcinoma: phase III randomized trial. J Natl Cancer Inst 2011, 103(23):1761-1770.

25. Chen L, Hu CS, Chen XZ, Hu GQ, Cheng ZB, Sun Y, Li WX, Chen YY, Xie FY, Liang SB, Chen Y, Xu TT, Li B, Long GX, Wang SY, Zheng BM, Guo Y, Mao YP, Tang LL, Chen YM, Liu MZ, Ma J: Concurrent chemoradiotherapy plus adjuvant chemotherapy versus concurrent chemoradiotherapy alone in patients with locoregionally advanced nasopharyngeal carcinoma: a phase 3 multicentre randomised controlled trial. Lancet Oncol 2012, 13(2):163-171

26. Lo YM, Chan LY, Lo KW, Leung SF, Zhang J, Chan AT, Lee JC, Hjelm NM, Johnson PJ, Huang DP: Quantitative analysis of cell-free Epstein-Barr virus DNA in plasma of patients with nasopharyngeal carcinoma. Cancer Res 1999, 59(6):1188-1191.

27. Shao JY, Li YH, Gao HY, Wu QL, Cui NJ, Zhang L, Cheng G, Hu LF, Ernberg I, Zeng YX: Comparison of plasma Epstein-Barr virus (EBV) DNA levels and serum EBV immunoglobulin A/virus capsid antigen antibody titers in patients with nasopharyngeal carcinoma. Cancer 2004, 100(6):1162-1170.

28. An X, Wang FH, Ding PR, Deng L, Jiang WQ, Zhang L, Shao JY, Li YH: Plasma Epstein-Barr virus DNA level strongly predicts survival in metastatic/ recurrent nasopharyngeal carcinoma treated with palliative chemotherapy. Cancer 2011, 117(16):3750-3757.

29. Chan AT, Lo YM, Zee B, Chan LY, Ma BB, Leung SF, Mo F, Lai M, Ho S, Huang DP, Johnson PJ: Plasma Epstein-Barr virus DNA and residual disease after radiotherapy for undifferentiated nasopharyngeal carcinoma. J Natl Cancer Inst 2002, 94(21):1614-1619.

30. Liu Y, Huang Q, Liu W, Liu Q, Jia W, Chang E, Chen F, Liu Z, Guo X, Mo H, Chen J, Rao D, Ye W, Cao S, Hong M: Establishment of VCA and EBNA1 IgA-based combination by enzyme-linked immunosorbent assay as preferred screening method for nasopharyngeal carcinoma: a twostage design with a preliminary performance study and a mass screening in southern China. Int J Cancer 2012, 131(2):406-416.

31. Franchini M, Montagnana M, Targher G, Manzato F, Lippi G: Pathogenesis, clinical and laboratory aspects of thrombosis in cancer. J Thromb Thrombolysis 2007, 24(1):29-38.

32. Liu L, Zhang X, Yan B, Gu Q, Jiao J, Sun D, Wang N, Yue X: Elevated plasma D-dimer levels correlate with long term survival of gastric cancer patients. PLoS One 2014, 9(3):e90547.

33. Ay C, Dunkler D, Pirker R, Thaler J, Quehenberger P, Wagner O, Zielinski C, Pabinger I: High D-dimer levels are associated with poor prognosis in cancer patients. Haematologica 2012, 97(8):1158-1164.

34. Ma BB, King A, Lo YM, Yau YY, Zee B, Hui EP, Leung SF, Mo F, Kam MK, Ahuja A, Kwan WH, Chan AT: Relationship between pretreatment level of plasma Epstein-Barr virus DNA, tumor burden, and metabolic activity in advanced nasopharyngeal carcinoma. Int J Radiat Oncol Biol Phys 2006, 66(3):714-720.

35. Lo YM, Leung SF, Chan LY, Lo KW, Zhang J, Chan AT, Lee JC, Hjelm NM, Johnson PJ, Huang DP: Plasma cell-free Epstein-Barr virus DNA quantitation in patients with nasopharyngeal carcinoma. Correlation with clinical staging. Ann N Y Acad Sci 2000, 906:99-101.

36. Lo YM, Chan LY, Chan AT, Leung SF, Lo KW, Zhang J, Lee JC, Hjelm NM, Johnson PJ, Huang DP: Quantitative and temporal correlation between circulating cell-free Epstein-Barr virus DNA and tumor recurrence in nasopharyngeal carcinoma. Cancer Res 1999, 59(21):5452-5455.

37. Song C, Yang S: A meta-analysis on the EBV DNA and VCA-IgA in diagnosis of Nasopharyngeal Carcinoma. Pak J Med Sci 2013, 29(3):885-890.

38. Leung SF, Chan KC, Ma BB, Hui EP, Mo F, Chow KC, Leung L, Chu KW, Zee B, Lo YM, Chan AT: Plasma Epstein-Barr viral DNA load at midpoint of radiotherapy course predicts outcome in advanced-stage nasopharyngeal carcinoma. Ann Oncol 2014, 25(6):1204-1208.

39. Kasthuri RS, Taubman MB, Mackman N: Role of tissue factor in cancer. J Clin Oncol 2009, 27(29):4834-4838.

40. Liu N, Chen NY, Cui RX, Li WF, Li Y, Wei RR, Zhang MY, Sun Y, Huang BJ, Chen M, He QM, Jiang N, Chen L, Cho WC, Yun JP, Zeng J, Liu LZ, Li L, Guo Y, Wang HY, Ma J: Prognostic value of a microRNA signature in nasopharyngeal carcinoma: a microRNA expression analysis. Lancet Oncol 2012, 13(6):633-641.

41. Wang HY, Sun BY, Zhu ZH, Chang ET, To KF, Hwang JS, Jiang H, Kam MK, Chen G, Cheah SL, Lee M, Liu ZW, Chen J, Zhang JX, Zhang HZ, He JH, Chen FL, Zhu XD, Huang MY, Liao DZ, Fu J, Shao Q, Cai MB, Du ZM, Yan LX, Hu CF, Ng HK, Wee JT, Qian CN, Liu Q, et al: Eight-signature classifier for prediction of nasopharyngeal [corrected] carcinoma survival. J Clin Oncol 2011, 29(34):4516-4525.

42. Ay C, Vormittag R, Dunkler D, Simanek R, Chiriac AL, Drach J, Quehenberger P, Wagner O, Zielinski C, Pabinger I: D-dimer and prothrombin fragment $1+2$ predict venous thromboembolism in 
patients with cancer: results from the Vienna Cancer and Thrombosis Study. J Clin Oncol 2009, 27(25):4124-4129.

43. Arpaia G, Carpenedo M, Verga M, Mastrogiacomo O, Fagnani D, Lanfredini M, Milani M, Cimminiello C: D-dimer before chemotherapy might predict venous thromboembolism. Blood Coagul Fibrinolysis 2009, 20(3):170-175.

doi:10.1186/1471-2407-14-583

Cite this article as: Chen et al: Elevated levels of plasma D-dimer predict a worse outcome in patients with nasopharyngeal carcinoma. BMC Cancer 2014 14:583.

\section{Submit your next manuscript to BioMed Central and take full advantage of:}

- Convenient online submission

- Thorough peer review

- No space constraints or color figure charges

- Immediate publication on acceptance

- Inclusion in PubMed, CAS, Scopus and Google Scholar

- Research which is freely available for redistribution 